\title{
TU/e emonownen

\section{Charge transfer to a dielectric target by guided ionization waves using electric field measurements}

\section{Citation for published version (APA):}

Slikboer, E. T., Garcia-Caurel, E., Guaitella, O., \& Sobota, A. (2017). Charge transfer to a dielectric target by guided ionization waves using electric field measurements. Plasma Sources Science and Technology, 26(3), 114. [035002]. https://doi.org/10.1088/1361-6595/aa53fe

\section{Document license:}

TAVERNE

DOI:

10.1088/1361-6595/aa53fe

Document status and date:

Published: 06/02/2017

\section{Document Version:}

Publisher's PDF, also known as Version of Record (includes final page, issue and volume numbers)

\section{Please check the document version of this publication:}

- A submitted manuscript is the version of the article upon submission and before peer-review. There can be important differences between the submitted version and the official published version of record. People interested in the research are advised to contact the author for the final version of the publication, or visit the $\mathrm{DOI}$ to the publisher's website.

- The final author version and the galley proof are versions of the publication after peer review.

- The final published version features the final layout of the paper including the volume, issue and page numbers.

Link to publication

\section{General rights}

Copyright and moral rights for the publications made accessible in the public portal are retained by the authors and/or other copyright owners and it is a condition of accessing publications that users recognise and abide by the legal requirements associated with these rights.

- Users may download and print one copy of any publication from the public portal for the purpose of private study or research.

- You may not further distribute the material or use it for any profit-making activity or commercial gain

- You may freely distribute the URL identifying the publication in the public portal.

If the publication is distributed under the terms of Article 25fa of the Dutch Copyright Act, indicated by the "Taverne" license above, please follow below link for the End User Agreement:

www.tue.nl/taverne

Take down policy

If you believe that this document breaches copyright please contact us at:

openaccess@tue.nl

providing details and we will investigate your claim. 
Charge transfer to a dielectric target by guided ionization waves using electric field measurements

This content has been downloaded from IOPscience. Please scroll down to see the full text. 2017 Plasma Sources Sci. Technol. 26035002

(http://iopscience.iop.org/0963-0252/26/3/035002)

View the table of contents for this issue, or go to the journal homepage for more

Download details:

IP Address: 131.155.151.148

This content was downloaded on 28/03/2017 at 08:42

Please note that terms and conditions apply.

You may also be interested in:

Time-resolved electric field measurements during and after the initialization of a $\mathrm{kHz}$ plasma jet-from streamers to guided streamers

Elmar Slikboer, Olivier Guaitella and Ana Sobota

Electric field measurements in a $\mathrm{kHz}$-driven $\mathrm{He}$ jet-the influence of the gas flow speed A Sobota, O Guaitella, G B Sretenovi et al.

The impingement of a $\mathrm{kHz}$ helium atmospheric pressure plasma jet on a dielectric surface O Guaitella and A Sobota

$\underline{\text { Phase-resolved measurement of electric charge deposited by an atmospheric pressure plasma jet on a }}$ dielectric surface

R Wild, T Gerling, R Bussiahn et al.

On atmospheric-pressure non-equilibrium plasma jets and plasma bullets

X Lu, M Laroussi and V Puech

Experimentally obtained values of electric field of an atmospheric pressure plasma jet impinging on a dielectric surface

A Sobota, O Guaitella and E Garcia-Caurel

Numerical and experimental study of the dynamics of a s helium plasma gun discharge with various amounts of $\mathrm{N} 2$ admixture

Anne Bourdon, Thibault Darny, François Pechereau et al.

The influence of the geometry and electrical characteristics on the formation of the atmospheric pressure plasma jet

A Sobota, O Guaitella and A Rousseau 


\title{
Charge transfer to a dielectric target by guided ionization waves using electric field measurements
}

\author{
Elmar Slikboer ${ }^{1,4}$, Enric Garcia-Caurel ${ }^{2}$, Olivier Guaitella ${ }^{3}$ and Ana Sobota ${ }^{1}$ \\ ${ }^{1}$ Department of Applied Physics, EPG, Eindhoven University of Technology, The Netherlands \\ ${ }^{2}$ LPP, CNRS, Ecole Polytechnique, UPMC, Université Paris-Saclay, 91128 Palaiseau, France \\ ${ }^{3}$ LPICM, CNRS, Ecole Polytechnique, Université Paris-Saclay, 91128 Palaiseau, France \\ E-mail: elmar.slikboer@lpp.polytechnique.fr
}

Received 8 August 2016, revised 25 November 2016

Accepted for publication 15 December 2016

Published 6 February 2017

\begin{abstract}
A kHz-operated atmospheric pressure plasma jet is investigated by measuring charge transferred to a dielectric electro-optic surface (BSO crystal) allowing for the measurement of electric field by exploiting the Pockels effect. The electric field values, distribution of the surface discharge and amount of deposited charge are obtained for various parameters, including gas flow, applied voltage, target distance and the length of the capillary from ground to the end. A newly formed surface discharge emerges at the target when enough charge is deposited at the impact point and electric fields are high enough, i.e. $200 \mathrm{pC}$ and $9 \pm 2 \mathrm{kV} \mathrm{cm}^{-1}$. The maximum amount of charge transferred by a single ionization wave ('plasma bullet') is $350 \pm 40 \mathrm{pC}$. Due to the emerging new surface discharge behind the impact point, the total charge deposited on the surface of the dielectric target can increase up to $950 \mathrm{pC}$. The shape of the secondary discharge on the target is found to be mainly driven by gas flow, while the applied voltage allows us to utilize longer distances within the boundaries set by this gas mixing. Finally the ionization wave is found to lose charge along its propagation on the inner walls of the capillary. The loss is estimated to be approximately $7.5 \mathrm{pC} \mathrm{mm}^{-1}$ of travel distance inside the capillary.
\end{abstract}

Keywords: electric field, guided ionization waves, plasma bullets, atmospheric pressure plasma jet, Pockels effect, charge transfer, dielectric target

(Some figures may appear in colour only in the online journal)

\section{Introduction}

Atmospheric pressure plasma jets have been introduced in the last decade for the purpose of surface treatment and plasma medicine [1-7]. Besides the investigation of radio frequency (RF) powered plasmas, a significant amount of work has been done investigating guided ionization waves produced using a pulsed DC or AC system [8]. Many different atmospheric pressure plasma jet designs are presented in the literature [9]. As such every jet system will have its own operating parameters concerning applied voltages and frequency, amount of gas flow, type of gas, capillary dimensions and design regarding distances between the electrodes, capacitance, etc.

4 Author to whom any correspondence should be addressed.
From an application point of view often a target is treated by delivering the so-called plasma cocktail to the surface, containing charged species, radicals, electric field, (UV) radiation and heat [10]. Therefore the exposure time and distance to target are additional parameters important for the understanding of the effects on the target [11].

This work presents electric field measurements of guided ionization waves on the surface of an electro-optic BSO $\left(\mathrm{Bi}_{12} \mathrm{SiO}_{20}\right)$ crystal produced using an atmospheric pressure plasma jet. The electric field measurements are used to calculate the amount of charge deposited on the dielectric target.

Guided ionization waves are also referred to as plasma bullets or guided streamers in the literature and the key difference with regular streamers is their reproducibility. It is assumed that the preferred trajectory for guided ionization 
waves is caused either by gas mixing effects (the front propagates in the more favourable noble gas atmosphere) or that the leftover ionization and metastables from previous discharges create a memory effect, or both. Recently reproducible surface discharges have been observed [11] and it has been shown [12] that streamer-to-bullet transition takes approximately a second on the surface of a BSO crystal.

The size of guided ionization waves depends on the jet design and other operating parameters, but at atmospheric pressure they are a few millimetres at most [11, 13, 14]. As such they are easily influenced and metallic probes or antennas are not ideal for electric field measurements. Dielectric BSO surfaces provide a less intrusive way of measuring electric field, both spatially and time resolved. Where (metallic) probes perturb the discharge as well, the dielectric BSO surface allows for the investigation of a discharge closely related to the discharges applied in practice to dielectric surfaces. Previous work [15] has been performed on a similar system where the target dielectric was in contact with a large grounded plane, which inevitably changed the properties of the ionization wave. There are, consequently, a number of effects that have been observed in the setup used in this work and not in the setup in [15], such as the elaborate evolution of surface discharges [11] whose properties can be quantitatively discussed using the electric field measurements presented in this paper.

The general aim of this article is to gain better understanding of the influence of plasma jet operating parameters on guided ionization waves in the presence of a dielectric target. The main focus lies in the influence of the applied voltage, helium gas flow, position of the ground and target distance. This is investigated by measuring the electric field, capturing the distribution of surface discharge and calculating the amount of charge deposited on the surface.

Relevant for the use of the Pockels effect for similar purposes, this article presents remarks that are of importance when measuring inhomogeneous electric field or surface charge.

\section{Pockels effect for electric field determination}

The Pockels effect is the electro-optical property of a class of materials in which the refractive index of the material changes linearly with applied electric field. Moreover, different values for refractive indices can be induced along different crystal axes. Consequently, if light passes through such a material, depending on its polarization state, a retardance is induced which can be measured using e.g. the Sénarmont setup, shown in figure 1. Previous studies used the Pockels effect for the investigation of streamers [17], but also the electric field induced by guided ionization waves $[15,16,18]$.

In figure 1 the setup is shown, where the light first passes through a polarizer at 45 degrees, then through the Pockelsactive crystal and finally through a quarter wave plate. Retardance is induced by a certain local distribution of charge on one side of the crystal. The final polarizer, i.e. the analyzer, is used to probe the final polarization state of the light.

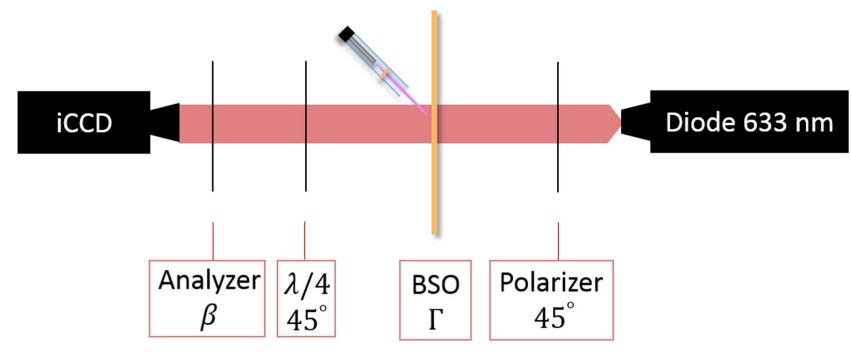

Figure 1. The Sénarmont setup used for electric field measurements based on the Pockels effect. The transmission depends on the retardance $\Gamma$, induced by charges deposited on the surface of the crystal, and the angle $\beta$ of the analyzer $[12,16]$. The axis to which the light propagates along is referred to as the $z$-axis.

The intensity of light reaching the detector is dependent on the angle $\beta$ and the retardance $\Gamma$ induced in the crystal.

For light passing through the Pockels-active crystal at normal incidence (i.e. along the $z$-axis) the phase velocity difference $\Delta v_{p}$ induced by the Pockels effect causes a delay $\Gamma$ experienced in the crystal. Besides the wavelength of the light $\lambda=633 \mathrm{~nm}$, the index of refraction $n_{0}=2.54$, the crystal thickness $d=0.5 \mathrm{~mm}$ and the Pockels coefficient $r_{41}=4.8 \mathrm{pm}$ $\mathrm{V}^{-1}$ [16], retardance depends on the electric field parallel to the propagation direction of the incident light. The distribution of electric field (strength) throughout the thickness of the crystal will affect the retardance, and the usual expression relates the average electric field strength $\overline{E_{z}}$ to the retardance according to

$$
\begin{aligned}
\Gamma(x, y) & =k_{0} \Lambda \\
& =\frac{2 \pi}{\lambda} \int_{0}^{d} \Delta n(x, y) \mathrm{d} z \\
& =\frac{2 \pi}{\lambda} \cdot n_{0}^{3} r_{41} \int_{0}^{d} E_{z}(x, y, z) \mathrm{d} z \\
& =\frac{2 \pi d}{\lambda} \cdot n_{0}^{3} r_{41} \overline{E_{z}(x, y)} .
\end{aligned}
$$

According to Sénarmont's setup, when measuring at halfmaximum of the transmission curve, the recorded intensity is a linear function of retardance [19], and the average electric field can be expressed as follows:

$$
\overline{E_{z}(x, y)}=\frac{\lambda}{\pi d n_{0}^{3} r_{41}} \frac{I-I_{0}}{I_{\max }-I_{\min }} .
$$

Half-maximum intensity is found by rotating the analyzer by an adequate angle beta. $I$ and $I_{0}$ are the measured light intensities, obtained at $50 \%$ transmittance in order to linearize the transmission function, respectively with charge on the crystal and without. The intensity difference is normalized using the maximum intensity $I_{\max }$ and minimum intensity $I_{\min }$ by changing the analyzer to $55^{\circ}$ and $145^{\circ}$, without charge on the crystal. The extra $10^{\circ}$ comes from the rotary power of the BSO material and is not related to the applied electric field, as such $50 \%$ transmittance is reached when $\beta=100^{\circ}[19,20]$.

When the thickness $d$ of the crystal is small in comparison with the area $A$ over which charge $Q$ is spread, the electric field inside the crystal can be approximated to be uniform. This depends on the surface charge $\sigma$ and the dielectric constant of the material $\varepsilon_{r}=56$ for the BSO 
$\left(\mathrm{Bi}_{12} \mathrm{SiO}_{20}\right)$ crystal [21]

$$
E_{z}=\frac{\sigma}{2 \varepsilon_{0} \varepsilon_{r}}=\frac{Q}{2 \varepsilon_{0} \varepsilon_{r} A}
$$

The factor 2 is included since in this case the charge is only deposited on one side of the crystal. When the uniform field approximation is valid this can be used to calculate the amount of (surface) charge present by using the measured electric field obtained with the Pockels effect.

If the charge is distributed over a surface that is comparable to or smaller than the thickness of the crystal, e.g. when using a plasma jet on a $0.5 \mathrm{~mm}$ thick crystal, the validity of the uniform field approximation is questionable. The validity of the uniform field approximation can be examined numerically by comparing the average field inside the crystal-which is the one measured with the Pockels effect-with the surface field value. For that purpose the electric field inside the crystal is calculated using Coulomb's integration law for a uniformly charged disk of variable size at the surface of the crystal.
Clearly visible is that the uniform field approximation is only valid when the diameters $R_{x}$ and $R_{y}$ of the uniformly charged disks are at least one order of magnitude larger than the thickness of the crystal $d$. The ratio decreases from $95 \%$ to approximately $5 \%$ for $10^{-1}<R / d<10^{+1}$, which is usually the range at which filamentary plasmas are examined using the Pockels effect [15, 22-25]. Consequently, the electric field measured shows the average throughout the target material, which is still relevant for applications [26], but not the electric field strength on the crystal surface. Additionally, this value can therefore not be used to calculate the surface charge directly. Mu et al [27] already showed that the uniform field approximation cannot be used when the electric field in the dielectric target is highly non-homogeneous. Electric field profiles obtained numerically by Norberg et al [28] show that indeed this is the case.

Nevertheless, the value for the total surface charge obtained with the uniform field approximation can be corrected by using the values in a figure similar to figure 3 . Therefore the size (area) of the charged spot is needed, in

$$
\left(E_{x}, E_{y}, E_{z}\right)=\left\{\begin{array}{l}
E_{x}(x, y, z)=\frac{\sigma_{c}}{4 \pi \varepsilon_{0} \varepsilon_{r}} \int_{-b}^{b} \int_{-a \sqrt{1-j^{2} / b^{2}}}^{a \sqrt{1-j^{2} / b^{2}}} \frac{x-i}{\left((x-i)^{2}+(y-j)^{2}+z^{2}\right)^{3 / 2}} \mathrm{~d} i \mathrm{~d} j \\
E_{y}(x, y, z)=\frac{\sigma_{c}}{4 \pi \varepsilon_{0} \varepsilon_{r}} \int_{-a}^{a} \int_{-b \sqrt{1-i^{2} / a^{2}}}^{b \sqrt{1-i^{2} / a^{2}}} \frac{y-j}{\left((x-i)^{2}+(y-j)^{2}+z^{2}\right)^{3 / 2}} \mathrm{~d} j \mathrm{~d} i \\
E_{z}(x, y, z)=\frac{z \sigma_{c}}{4 \pi \varepsilon_{0} \varepsilon_{r}} \int_{-b}^{b} \int_{-a \sqrt{1-j^{2} / b^{2}}}^{a \sqrt{1-j^{2} / b^{2}}} \frac{1}{\left((x-i)^{2}+(y-j)^{2}+z^{2}\right)^{3 / 2}} \mathrm{~d} i \mathrm{~d} j
\end{array}\right.
$$

Figure 2 shows the axial and the radial electric field profiles inside the crystal at various positions $z$, where the charge is distributed over a circular surface whose radius is equal to the thickness of the crystal. The calculation is done using equation (4) for the electric field $\left(E_{x}, E_{y}, E_{z}\right)$ at $(x, y, z)$ inside the crystal for a uniformly charged disk at the surface $(z=0)$ with radii $a$ and $b$ equal to the thickness of the crystal, i.e. $0.5 \mathrm{~mm}$. The surface charge density $\sigma$ was set to $22 \mathrm{nC} \mathrm{cm}^{-2}$ because this value is of the order of magnitude present in our experiments.

Clearly visible is the decrease of the field through the thickness of the crystal. Consequently, when using the uniform field approximation for the calculation of the applied surface charge, compensation is necessary in this and similar conditions.

Figure 3 further explores the effects of using the uniform field approximation for small features of surface charge. Using the electric field profiles from figure 2, the average field through the crystal was calculated and then used to calculate the surface charge (equation (3)) $Q_{\text {ave }}$. This value was then compared to the true surface charge $Q_{\text {surf }}$ that was initially applied to the crystal. It shows, thus, the ratio of the true surface charge $Q_{\text {surf }}$ and the surface charge $Q_{\text {ave }}$ that would have been obtained when using the uniform field approximation. order that figure 3 can be used to match the measured value to the real surface value. Figure 3 is valid for the case of a uniform elliptical charge distribution. For example, if the radius of the circular spot of charge equals the thickness of the crystal, the measured total surface charge has to be multiplied by $\approx 1.5$ to obtain the true amount of surface charge. Again, a uniformly distributed surface charge is assumed for the calculation.

To obtain the value of electric field at the surface instead of averaged inside the target, a similar lookup table (or figure) can be used. Figure 4 gives an example of the ratio between the average throughout the thickness of the crystal and the surface value for the maximum electric field in the centre of the spot.

In the rest of the article this procedure for data correction for obtaining more accurate values for surface charge and surface electric field will be called compensation procedure.

\section{Experimental setup and data analysis}

The jet used in the experiments is shown in figure 5 and is described more comprehensively in [16]. Helium flows (0.5-1.5 SLM) through a stainless steel pipe acting as 


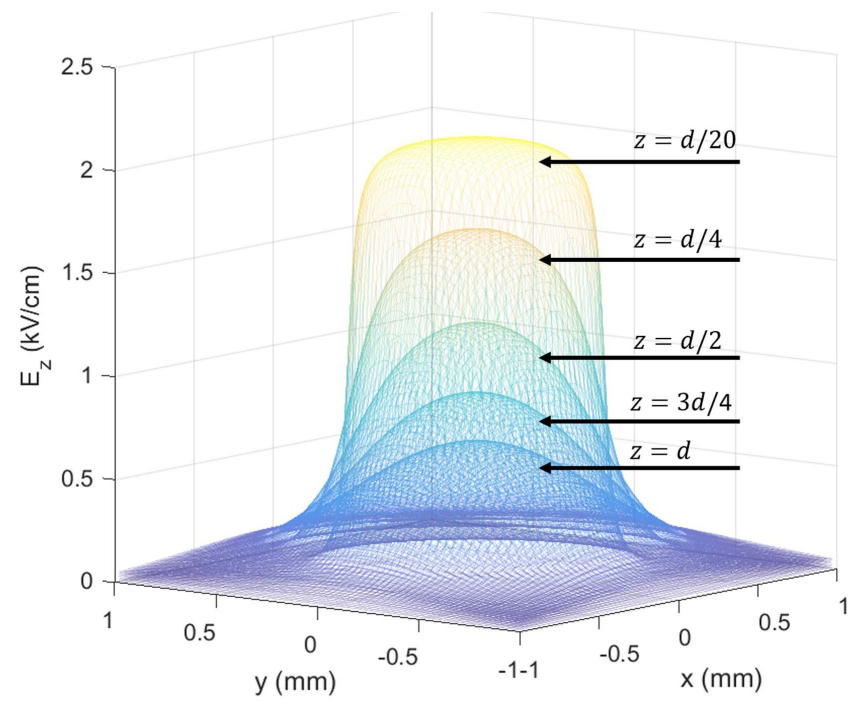

(a)

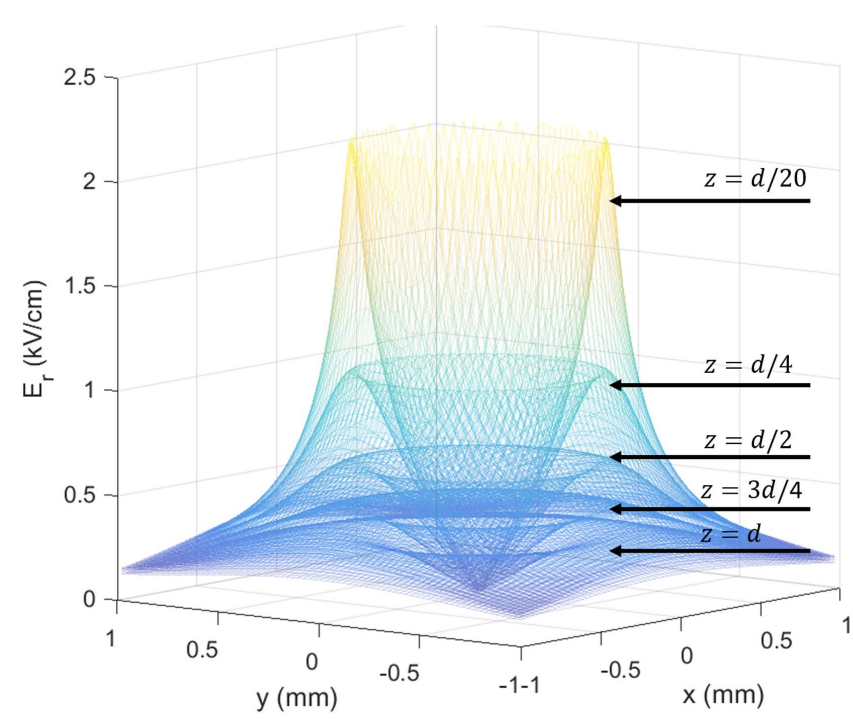

(b)

Figure 2. The electric field components, $E_{z}(x, y, z)$ in (a) and $E_{r}(x, y, z)$ in (b), throughout the crystal at $z=\{d / 20, d / 4, d / 2$, $3 d / 4$ and $d\}$, calculated using equation (4) for a spot with radius equal to the thickness of the crystal.

powered electrode operated at $30 \mathrm{kHz} \mathrm{AC}$ with an inner diameter of $0.8 \mathrm{~mm}$. The stainless steel capillary is housed in a larger dielectric Pyrex capillary (inner diameter $2.4 \mathrm{~mm}$ and outer diameter $4 \mathrm{~mm}$ ) that is open on one side. A copper ground $2 \mathrm{~mm}$ thick is attached on the outer side of the capillary. The source size is defined as the distance between the powered electrode and the copper ground. The distance from ground to the end of the capillary is called travelling distance throughout this paper. The position of the ground with regard to the end of the inner electrode and the length of the outer capillary are both varied, to examine the influence of both source size and travelling distance.

The reference settings are an applied voltage of $2 \mathrm{kV}$ amplitude (sine-wave AC, $4 \mathrm{kV}$ peak-to-peak), a helium flow

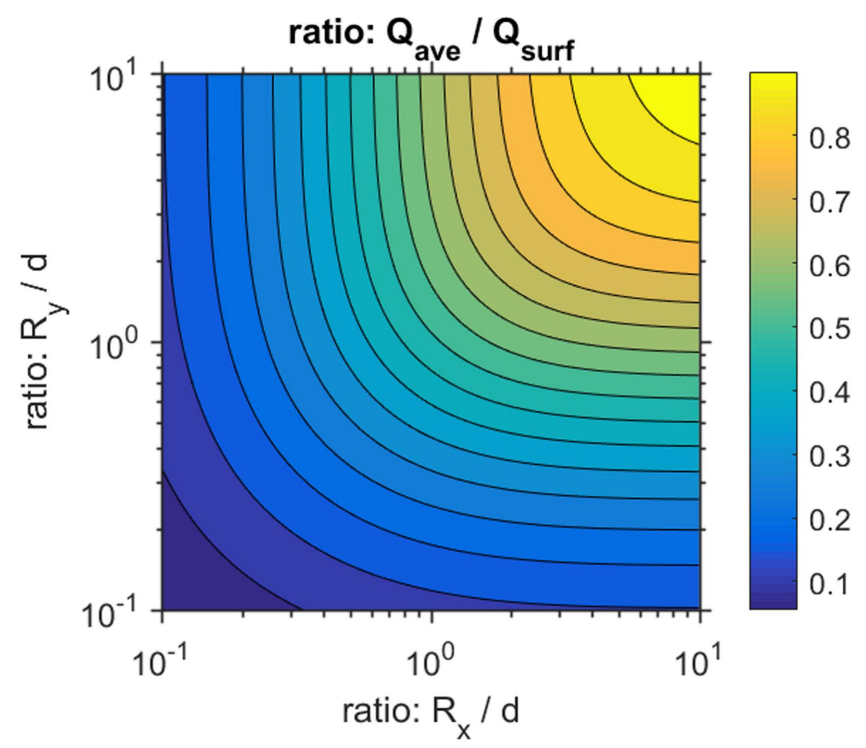

Figure 3. The ratio between the charge calculated using the unifrom field approximation $Q_{\text {ave }}$ and the actual charge on the surface of the crystal $Q_{\text {surf. }} R_{x}$ and $R_{y}$ are the axis lengths of the elliptical surface charge profile, and $d$ is the thickness of the crystal.

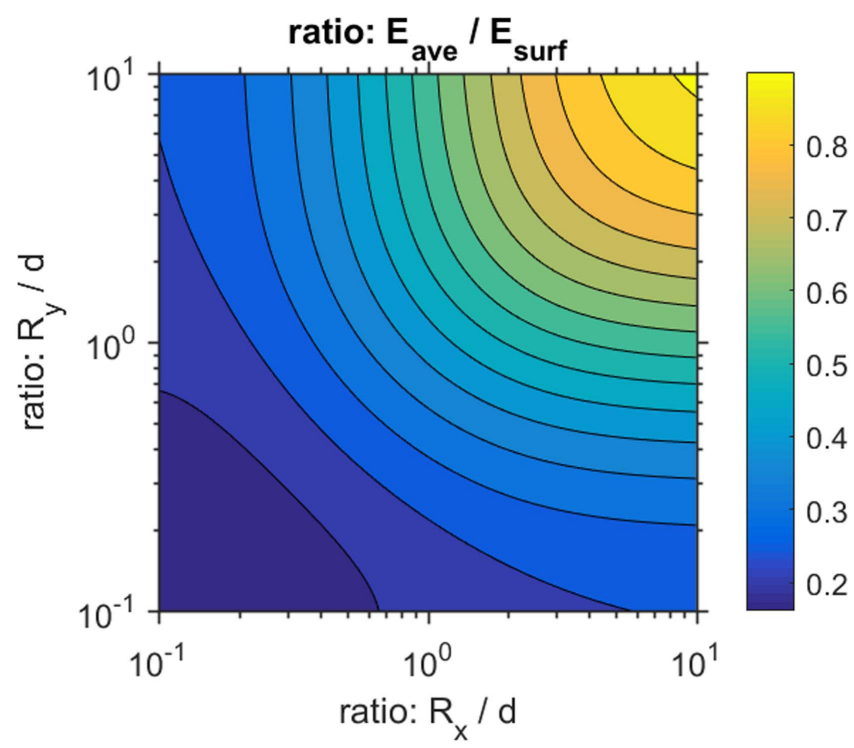

Figure 4. The ratio between the measured electric field $E_{\text {ave }}$ representing the average field throughout the thickness of the crystal and the field strength at the surface $E_{\text {surf }}$. Only the $z$ component is discussed. $R_{x}$ and $R_{y}$ are the axis lengths of the elliptical surface charge profile, and $d$ is the thickness of the crystal.

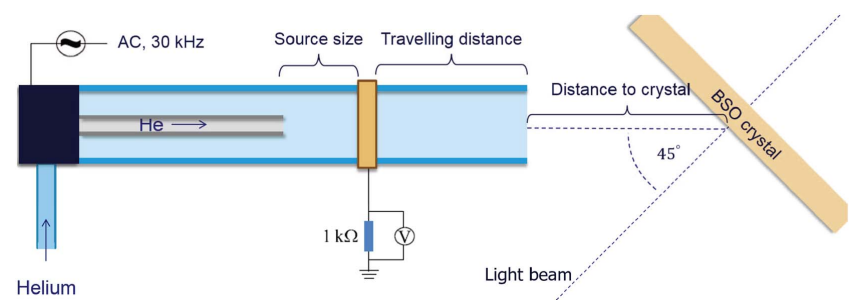

Figure 5. Top view of the setup used for producing guided ionizaton waves impinging the dielectric BSO crystal used for the measurements [16]. The source size, travelling distance and the distance to the crystal were varied in the experiments. 


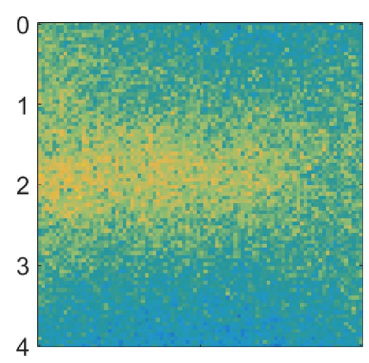

(a)

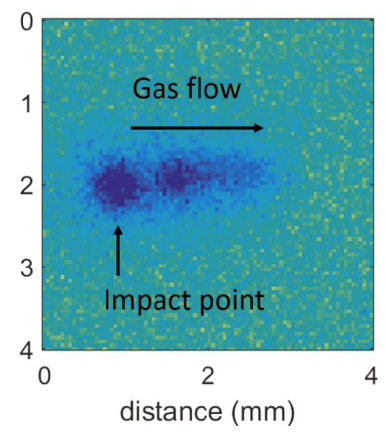

(c) (b)

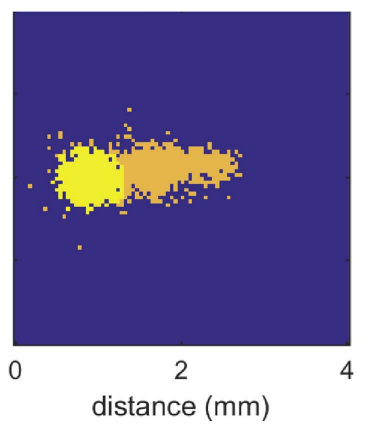

(d)

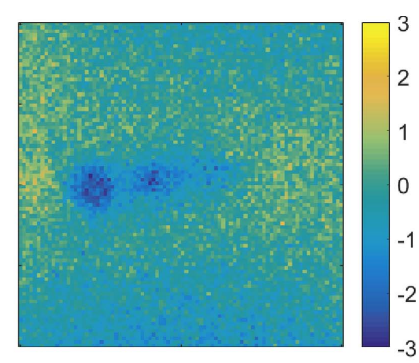

Figure 6. The electric field $\left(\mathrm{kV} \mathrm{cm}^{-1}\right)$ right before (a) and after (b) the guided ionization wave impacts. (c) shows the difference and (d) the mask which shows the pixels that are included in the calculation of total charge (yellow and orange) and spot charge (only yellow). Colorscale shown for (b) is also valid for (a) and (c). More information about the background structure is found in [12].

of $700 \mathrm{sccm}$, a source size of $5 \mathrm{~mm}$ and a travelling distance of $17 \mathrm{~mm}$. When operated at $30 \mathrm{kHz}$, the plasma jet produces exactly one ionization wave each period in the positive half cycle. This has been confirmed using fast imaging and current measurements at the ground.

The electric field is measured by making use of the Pockels effect, as described the previous section, on a $0.5 \mathrm{~mm}$ thick BSO $\left(\mathrm{Bi}_{12} \mathrm{SiO}_{20}\right)$ crystal. The jet was operated horizontally in a way that the symmetry axis of the jet is at 45 degrees relative to the surface of the BSO crystal.

The electric field measurements were performed timeresolved using an iCCD detector and $1 \mu$ s exposure times, averaged over 50 exposures. Determination of the electric field requires the measurement of four intensities (equation (3)): three reference intensities $I_{0}, I_{\max }$ and $I_{\min }$, as described in the previous section, and the intensity $I$ of the signal at the detector when the plasma is switched on.

Due to the existence of a background signal, as discussed in [12], the final result for the average electric field through the crystal has to be additionally corrected. For that reason a measurement is taken just before the guided ionization wave reaches the crystal, as shown in figure 6(a), which represents the background. This profile is subtracted from any other measurement after the ionization wave has reached the crystal (figure 6(b)) and their difference gives the true electric field profile (figure $6(\mathrm{c})$ ). The iCCD camera is triggered using the current peak measured at the ground around the capillary.

Some aspects of the dynamics of the plasma on the crystal surface have already been described in [12]. Upon impact of the ionization wave on the surface of the crystal, the charge remains on the crystal for approximately $13 \mu$ s after which a back discharge is initiated when the AC voltage changes polarity and an effective discharging is observed on the electric field profile. In this paper a lot of attention is given to the initial electric field and charge profile on the crystal surface caused by the ionization wave from the plasma jet and separately to the continuation of this discharge somewhat later in time. The initial profile is circular around the impact point of the ionization waves where charges are deposited on the surface (throughout the text referred to as the spot). The additional elongated structure observed extending along the direction of the gas flow for certain discharge parameters is referred to as the tail.

In order to separate the spot from the tail, as well as to ease the calculation of the associated surface charge and exclude noise from the other parts of the crystal, a mask was developed, shown in figure 6(d). To calculate the total charge a summation has to be done over the pixels relevant for either the initial impact spot (yellow in the figure) or the entire structure on the surface (orange and yellow in the figure). To create the mask a cutoff level of the electric field was applied, depending on the amount of noise but varying between 0.9 and $1.2 \mathrm{kV} \mathrm{cm}^{-1}$. The spot is chosen as the largest possible circular shape at the centre of the impact point.

Since the validity of the uniform field approximation depends on the surface discharge size, the dimensions are also obtained and the data from figures 3 and 4 are used to compensate the charge and electric field strength value for the inappropriate use of the uniform field approximation.

\section{Results}

\subsection{The effect of helium gas flow}

Helium flow is varied from $400 \mathrm{sccm}$ to $1300 \mathrm{sccm}$, while using reference settings for the remaining parameters. At $5 \mathrm{~mm}$ from the crystal, the measured average field in the target as a result of surface discharge is shown in figure 8 . For low flow the surface discharge is small and contains only the spot around the impact point. When the flow is increased, larger surface discharges are observed. At first the surface discharge is prolonged with higher flow, but from $900 \mathrm{sccm}$ the discharge is widened instead.

Maximum electric field values are taken in the spot at the impact point from figure 8 and compensated to estimate the value at the surface. Values are shown negative, since the electric field is oriented opposite to the propagation direction of the incident light. Where average values are measured between $3-6 \mathrm{kV} \mathrm{cm}^{-1}$ in the target, the surface values vary between $8-11 \mathrm{kV} \mathrm{cm}^{-1}$, see figure 7 . Higher values are measured with a larger gap between the jet and the target.

Since the measured electric field is negative, the deposited charges at the target side where the ionization waves impact have to be positive. This is because the ionization wave is generated only during the positive half period of the applied AC cycle. This relates with findings presented by 


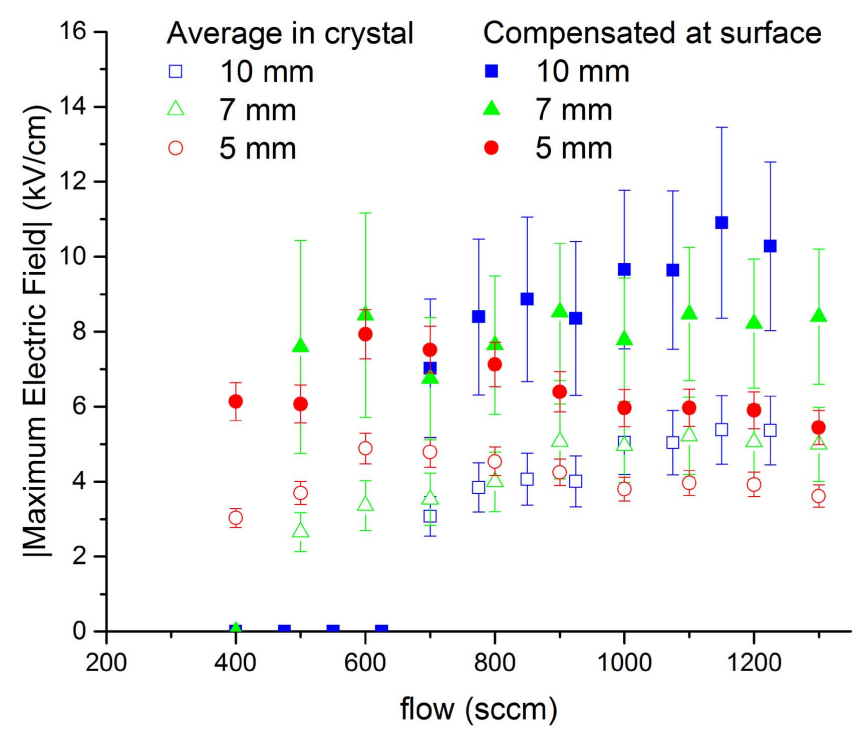

Figure 7. The maximum electric field values $\left(\mathrm{kV} \mathrm{cm}^{-1}\right)$ as a function of flow and distance to the target. Both the average throughout the thickness of the crystal and the compensated value for the field at the surface are given.

Pechereau et al, who found that the deposited charges on a dielectric target are of the same polarity as the voltage that is applied [29]. No ionization event is present during the negative half period, except for the (back) discharging at the surface of the crystal when the voltage polarity changes. This removes the earlier deposited charges [12].

Figure 9 shows the calculated and compensated amount of charge as a function of helium flow speed and the distance between the capillary and the crystal. Both the total surface charge and the charge in the spot are measured. At all distances there is an influence on the flow, extending the discharge behind the spot with an increase of flow. There is a clear onset point for the appearance of the tail: the elongated discharge behind the initial contact spot.

A minimum amount of charge deposited in the spot is required for the elongation of the discharge, i.e. approximately $200 \mathrm{pC}$. When the gap size between the jet and the target is small this is reached with a relatively low flow, 600 sccm, but for larger distances higher flows are needed, respectively 800 and $1200 \mathrm{sccm}$. Though the tail further increases in size with higher flow, the spot seems to be maximally increased to a point where $350 \pm 40 \mathrm{pC}$ is deposited. The total charge however can increase up to 950 pC. Figure 9 stresses the importance of the gas flow in combination with distance to the target.

\subsection{The effect of the applied voltage}

The influence of the applied voltage is examined under reference settings, by varying voltage amplitude from 1.2 to $2.3 \mathrm{kV}$. Figure 10 shows the measured electric field averaged throughout the thickness of the crystal caused by the impinging guided ionization waves, at $5 \mathrm{~mm}$ between the capillary and the crystal. With increasing applied voltages the surface discharge is enlarged to an extended discharge of $2-2.5 \mathrm{~mm}$ in length.

A minimum voltage with amplitude of $1.2 \mathrm{kV}$ is necessary for the plasma jet to operate continuously. From $1.2 \mathrm{kV}$ a steady state is reached where one guided ionization wave is created every two periods instead of one. Voltages of $1.4 \mathrm{kV}$ or higher generate one discharge every period, during the positive half-cycle. The applied voltage is not increased above $2.4 \mathrm{kV}$, since with this jet design micro-discharges appear at this voltage and dissipate heat, which can melt the capillary [30].

Maximum field values of the electric field in the target are obtained and used to estimate the field at the target's surface using the compensation procedure. The applied voltage does not seem to have a significant effect on the maximum induced values, which relate to the values shown in figure 7 , i.e. $9 \pm 2 \mathrm{kV} \mathrm{cm}^{-1}$.

The calculated and compensated charge is shown in figure 11. At standard conditions of $700 \mathrm{sccm}$ He flow at $5 \mathrm{~mm}$, the initial impact spot is extended with an additional surface discharge, even for low voltage. Again a minimal amount of 200 $\mathrm{pC}$ charge is needed, deposited in the initial spot, for the appeareance of the tail. The charge measured in the initial impact spot is a stable value for a given distance of the crystal from the capillary, from around $300 \pm 40 \mathrm{pC}$ at $5 \mathrm{~mm}$ to $140 \pm 30 \mathrm{pC}$ for the distance of $10 \mathrm{~mm}$. It has already been shown [12] that the extension of the discharge on the surface, the tail, appears later in time than the induced initial charge profile at the impact spot where the ionization waves reach the target.

The effect of voltage is less influential than gas flow, since the extended discharge behind the spot only appears when the jet is close to the crystal and the total charge is increased maximally up to $700 \mathrm{pC}$. The differences in influence with gas flow and voltage are clearly visualized in figures 12 and 13 . When the plasma jet is only $3 \mathrm{~mm}$ from the target, the surface discharges are very dependent on the gas flow. Unfortunately the capillary is partially blocking the view, making it impossible to calculate charges that are deposited. However, clearly visible with higher gas flow is that the extending tail splits up into two arms and widens significantly. The dependency with voltage is also visible and though the length of the tail is altered, the distribution is not.

\subsection{Source size and travelling distance}

The influence of both the source size and travelling distance of the discharge in the capillary is examined at standard conditions by varying the position of the grounded electrode attached around the outer capillary.

As visualized in the schematic representation in figure 5, travelling distance of the discharge in the capillary and source size are mutually dependent variables, connected through the length of the capillary. Figure 14 shows the effect for the surface discharge as a function of a change in the ground position at the capillary, varying from $4 \mathrm{~mm}$ to $11 \mathrm{~mm}$ away 


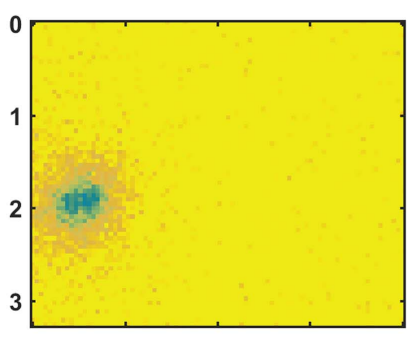

(a) $400 \mathrm{sccm}$

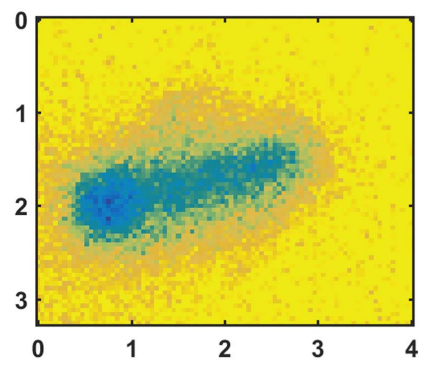

(e) $800 \mathrm{sccm}$

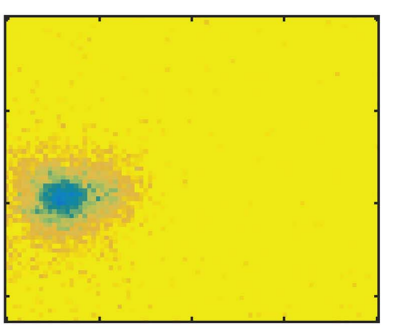

(b) $500 \mathrm{sccm}$

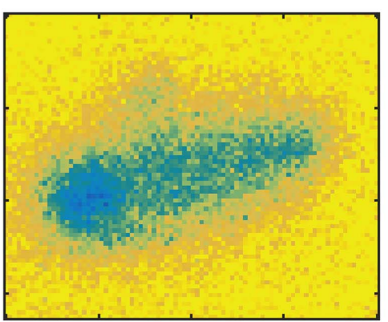

(f) $900 \mathrm{sccm}$

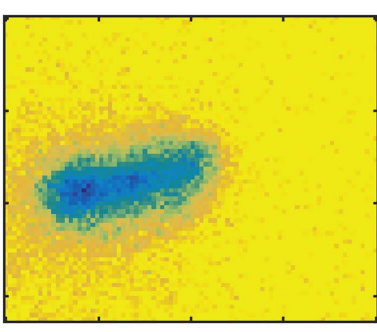

(c) $600 \mathrm{sccm}$

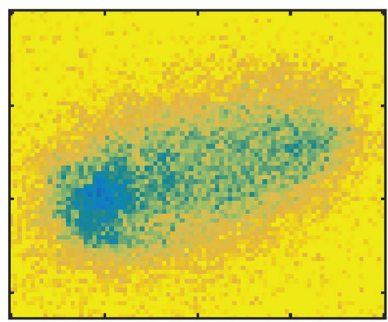

(g) $1000 \mathrm{sccm}$

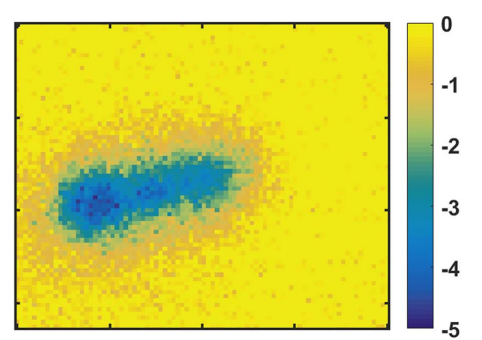

(d) $700 \mathrm{sccm}$

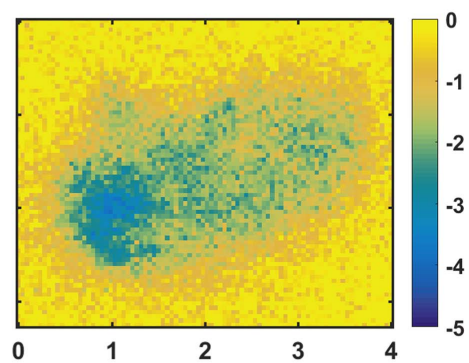

(h) $1100 \mathrm{sccm}$

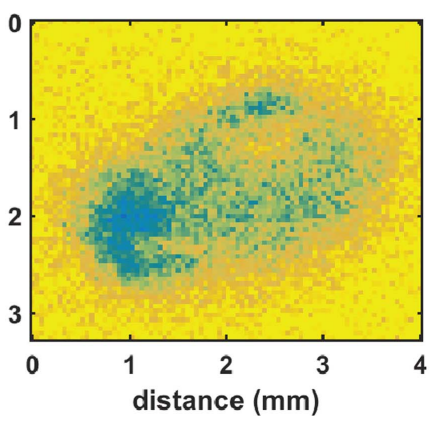

(i) $1200 \mathrm{sccm}$

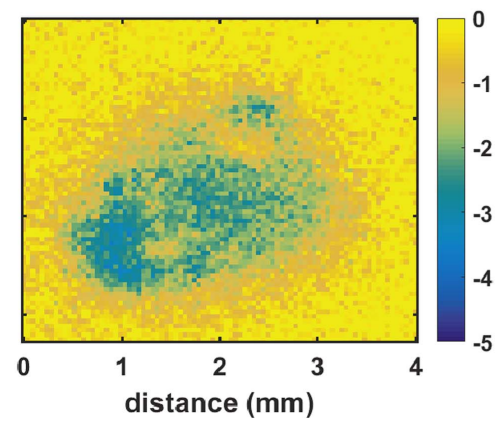

(j) $1300 \mathrm{sccm}$

Figure 8. The measured average electric field $\left(\mathrm{kV} \mathrm{cm}^{-1}\right)$ for varying speed of helium flow at $5 \mathrm{~mm}$ from the target. The induced retardance is measured right before and after the ionization wave impacts the crystal, averaging 50 exposures of $1 \mu \mathrm{s}$ with the plasma jet at reference settings.

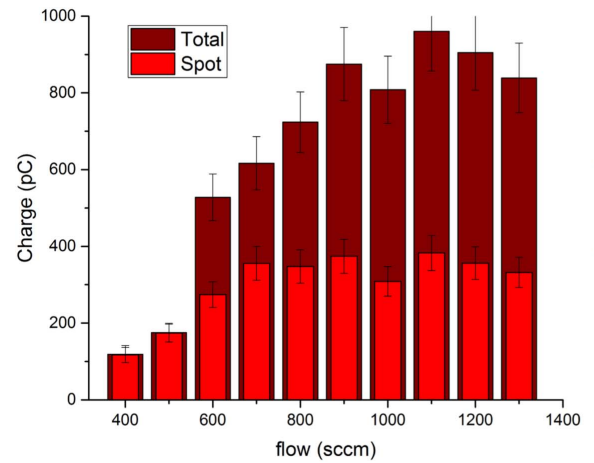

(a) $5 \mathrm{~mm}$

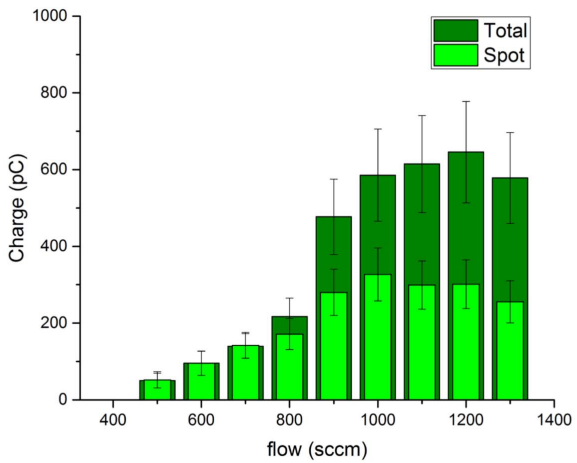

(b) $7 \mathrm{~mm}$

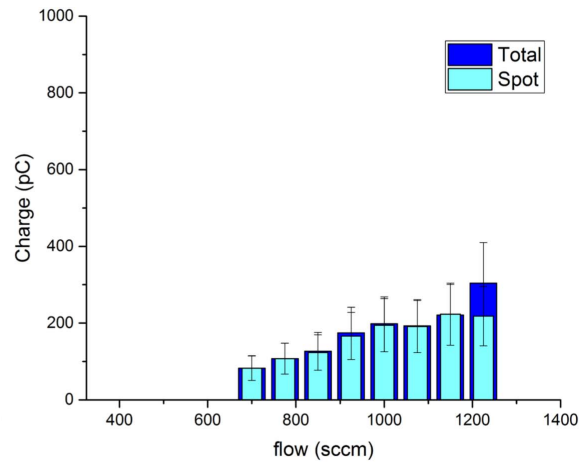

(c) $10 \mathrm{~mm}$

Figure 9. The compensated total surface charge for different flows and distances to the crystal. A distinction is made between total charge, containing the spot and tail, and solely the charge deposited at the spot around the impact point.

from the powered electrode. Since the combined length of source size and travelling distance for this capillary is $22 \mathrm{~mm}$, the travelling distance behind the ground automatically decreases from 18 to $11 \mathrm{~mm}$. At $7 \mathrm{~mm}$ distance between the capillary and the target this causes an increase in surface discharge, as is shown in figure 14.

By using two extra capillaries which are respectively 5 and $10 \mathrm{~mm}$ longer than the original one, the influence of 


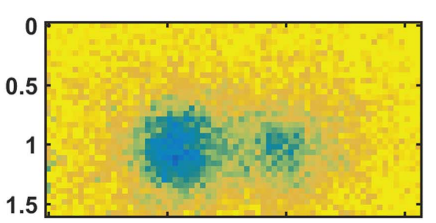

(a) $1.3 \mathrm{kV}$

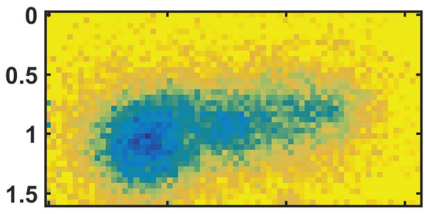

(e) $1.7 \mathrm{kV}$

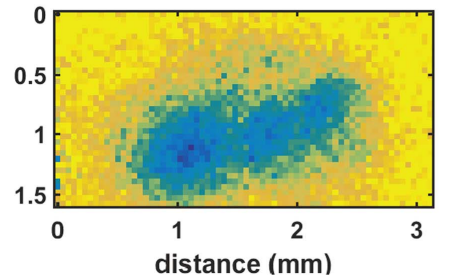

(i) $2.1 \mathrm{kV}$

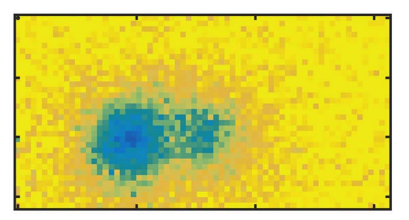

(b) $1.4 \mathrm{kV}$

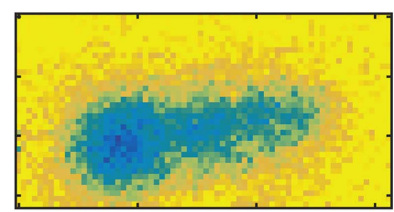

(f) $1.8 \mathrm{kV}$

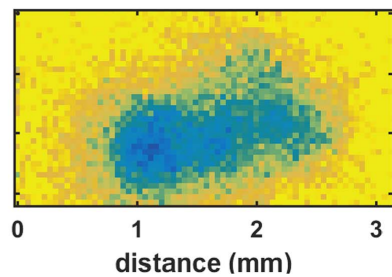

(j) $2.2 \mathrm{kV}$

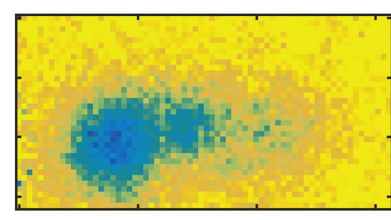

(c) $1.5 \mathrm{kV}$

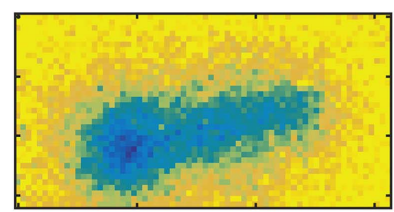

(g) $1.9 \mathrm{kV}$

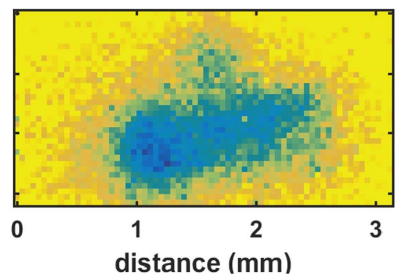

(k) $2.3 \mathrm{kV}$

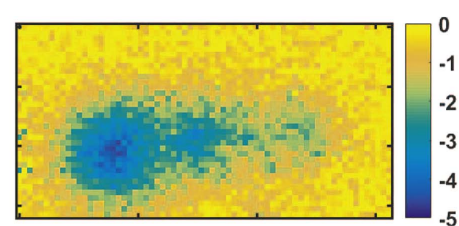

(d) $1.6 \mathrm{kV}$

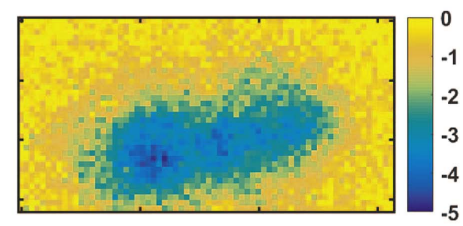

(h) $2.0 \mathrm{kV}$

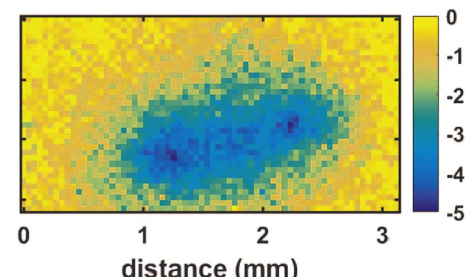

(l) $2.4 \mathrm{kV}$

Figure 10. The measured average electric field $\left(\mathrm{kV} \mathrm{cm}^{-1}\right)$ for varying voltage amplitude at $5 \mathrm{~mm}$ from the target. Again, similar to figure 8 , the field is obtained with $1 \mu \mathrm{s}$ imaging of the retardance right before and after the ionization waves reach the target.

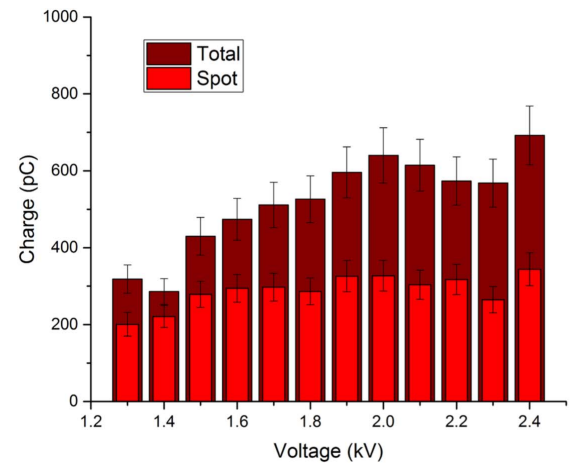

(a) $5 \mathrm{~mm}$

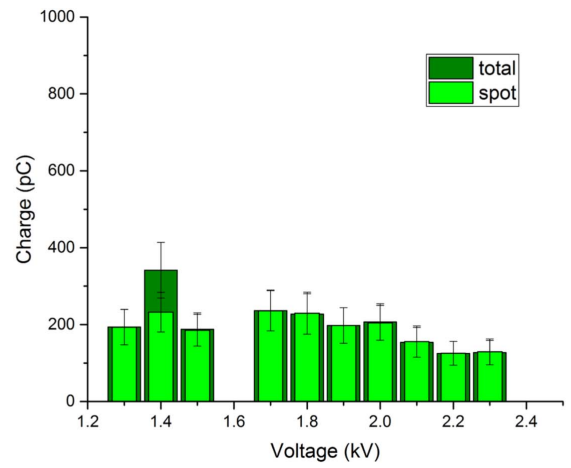

(b) $7 \mathrm{~mm}$

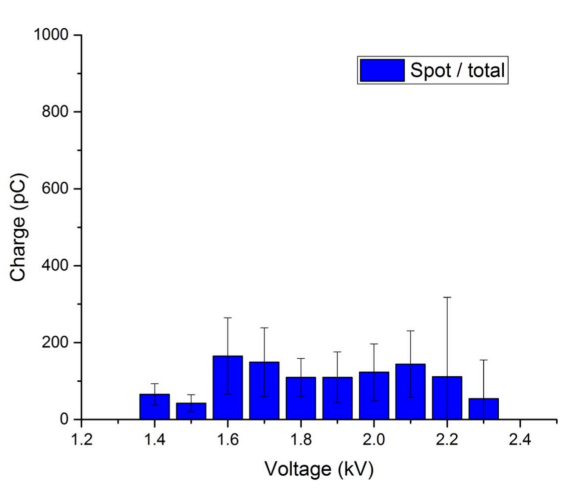

(c) $10 \mathrm{~mm}$

Figure 11. The compensated total surface charge for different voltage amplitudes and distances to the crystal. A distinction is made between total charge and the charge only in the spot.

source size and travelling distance can be separated. Figure 15 shows how charge measurements relate when having the same travelling distance but varying source size. At each distance between the jet and the target, the calculated total deposited charge on the target surface is approximately constant for measurements with the same travelling distance but varying source size. Only when the source size is increased above $15 \mathrm{~mm}$ does it influence the discharges, since no longer stable ionization waves are generated.

A change in travelling distance does influence the total charge deposited, especially with the jet positioned 7 or $10 \mathrm{~mm}$ from the target. Figure 16 shows the compensated and calculated amount of charge deposited on the target for varying travelling distances. At $10 \mathrm{~mm}$ distance between the jet and target not enough charge is deposited in the spot for the extending tail to be present. Less charge is deposited when the travelling distance is increased. A linear fit is used for the charge $Q$ in the spot in $\mathrm{pC}$ at the three different distances to the target as a function of the travelling distance $l$ in $\mathrm{mm}$ :

$$
\begin{aligned}
Q_{5 \mathrm{~mm}} & =(428 \pm 22)-(7.3 \pm 1) \cdot l \\
Q_{7 \mathrm{~mm}} & =(296 \pm 27)-(7.5 \pm 1) \cdot l \\
Q_{10 \mathrm{~mm}} & =(261 \pm 16)-(8.0 \pm 0.7) \cdot l .
\end{aligned}
$$

The linear relation is used to get an estimate for the loss term induced by interactions with the inner side of the capillary. Using the estimation from equation (5) it seems that approximately $7.5 \mathrm{pC}$ charge is lost in every millimetre of travelling distance inside the capillary. The offset in the empirically obtained relationship between the charge on the target and the travelling distance (equation (5)) varies with the distance to the crystal because of additional charge losses in air. 


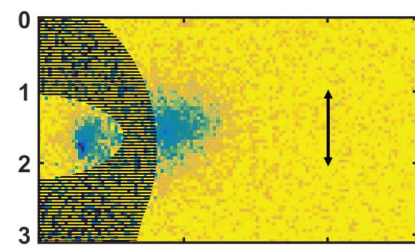

(a) $400 \mathrm{sccm}$

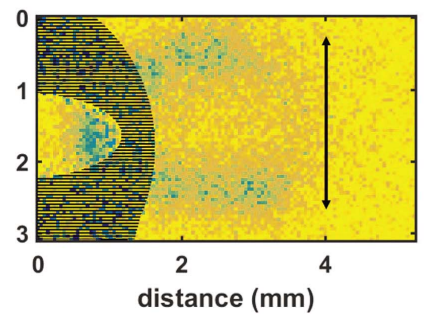

(e) $800 \mathrm{sccm}$

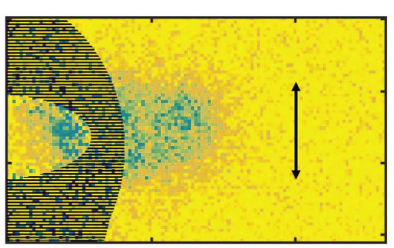

(b) $500 \mathrm{sccm}$

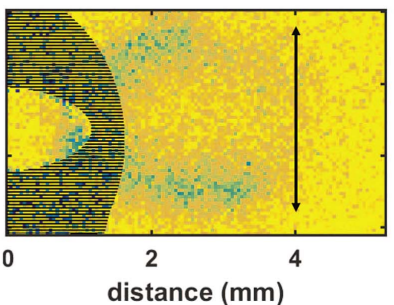

(f) $900 \mathrm{sccm}$

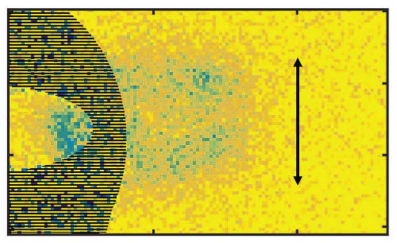

(c) $600 \mathrm{sccm}$

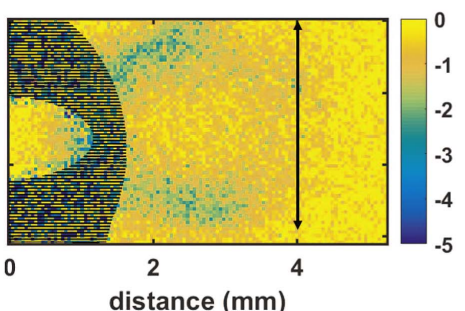

(g) $1000 \mathrm{sccm}$

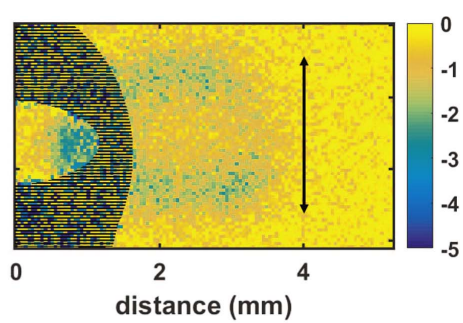

(d) $700 \mathrm{sccm}$

Figure 12. The electric field $\left(\mathrm{kV} \mathrm{cm}^{-1}\right)$ induced in the target with the plasma jet at $3 \mathrm{~mm}$ from the target for different gas flow (with $2 \mathrm{kV}$ applied voltage). The capillary partially blocks the view of the target. Higher flow causes widening of the surface discharges.

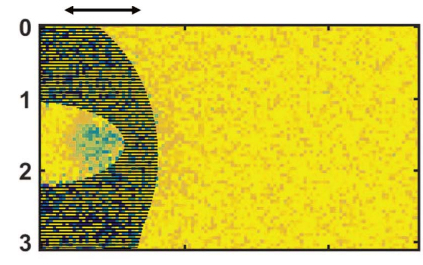

(a) $1.1 \mathrm{kV}$

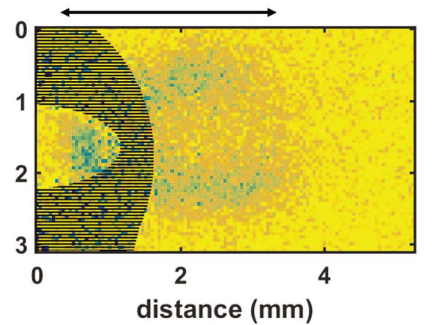

(e) $1.9 \mathrm{kV}$

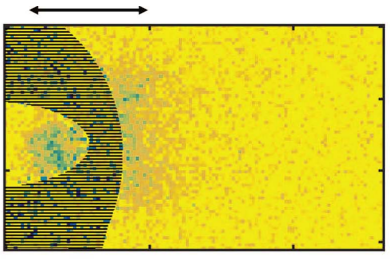

(b) $1.3 \mathrm{kV}$

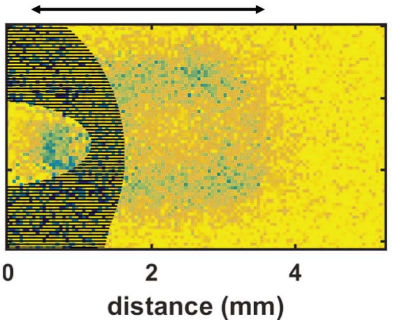

(f) $2.1 \mathrm{kV}$

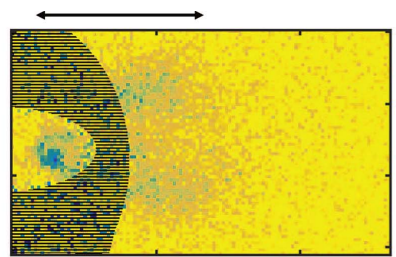

(c) $1.5 \mathrm{kV}$

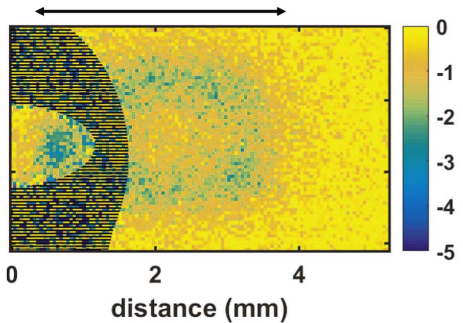

(g) $2.3 \mathrm{kV}$

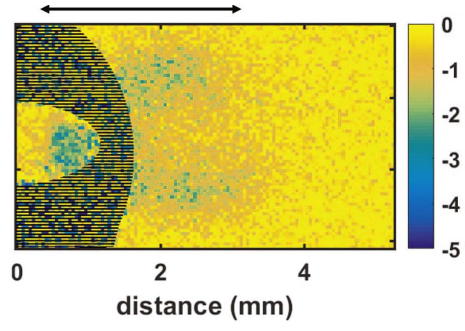

(d) $1.7 \mathrm{kV}$

Figure 13. The electric field $\left(\mathrm{kV} \mathrm{cm}^{-1}\right)$ induced with the plasma jet at $3 \mathrm{~mm}$ from the target for different voltage (with $700 \mathrm{sccm}$ gas flow). Again, the capillary partially blocks the view of the target. Higher voltage extends the surface discharges.

\section{Discussion}

There are several results that are of importance. Firstly the formation of an extension of the initial discharge on the surface of the dielectric target; secondly the influence of gas flow and applied voltage to the amount of charge deposited on the crystal; and thirdly the effect of the travel length on the amount of charge delivered to the dielectric target.

\subsection{Newly formed surface discharge}

It has already been shown that when ionization waves impact a dielectric target, it is possible to observe extended surface discharges [11]. The size and shape of these discharges depend mostly on the impact angle, distance to the dielectric target and gas flow. The same development in time has been reported with electric field measurements [12]. The process is as follows. First the ionization wave reaches the dielectric surface and forms a circular spot at the impact point in the case of the 45 degree impact angle. Subsequently another ionization front starts propagating on the dielectric surface, forming a tail whose shape and size depend on the gas flow and the distance between the capillary and the dielectric target $[11,12]$.

When there is visual contact between the plasma jet and the target, the measured spot in the electric field profile at the impact point is always present. However the extending tail appears only in certain conditions, e.g. for high gas flow and 


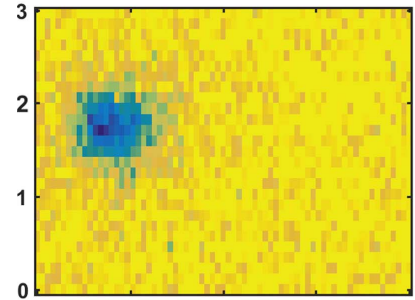

(a) $4 \mathrm{~mm} / 18 \mathrm{~mm}$

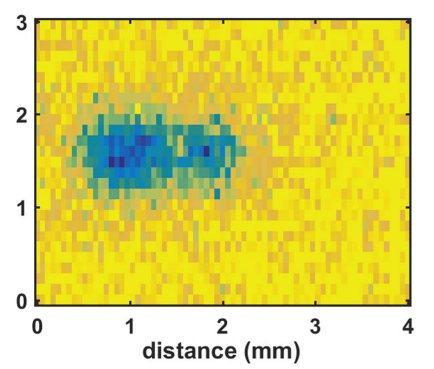

(e) $8 \mathrm{~mm} / 14 \mathrm{~mm}$

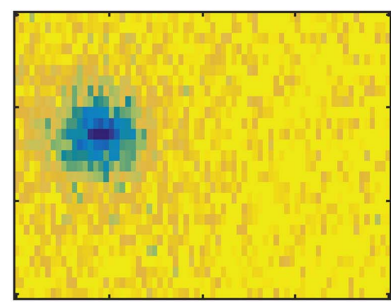

(b) $5 \mathrm{~mm} / 17 \mathrm{~mm}$

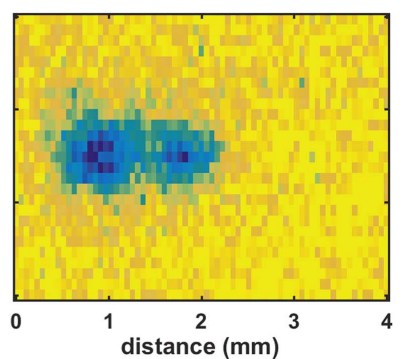

(f) $9 \mathrm{~mm} / 13 \mathrm{~mm}$

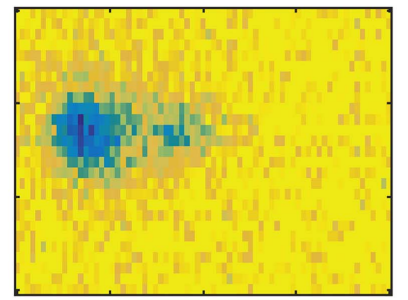

(c) $6 \mathrm{~mm} / 16 \mathrm{~mm}$

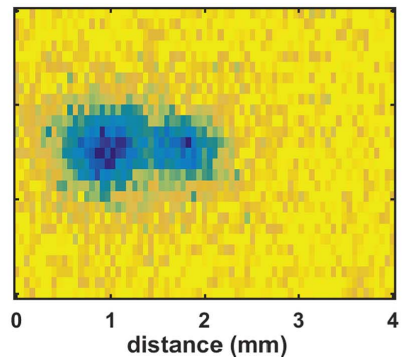

(g) $10 \mathrm{~mm} / 12 \mathrm{~mm}$

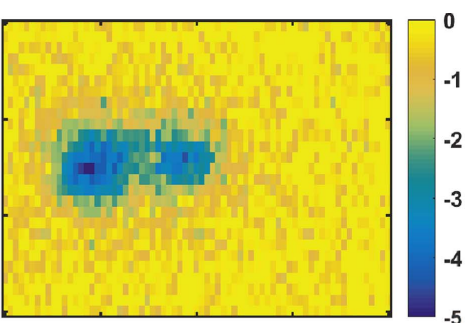

(d) $7 \mathrm{~mm} / 15 \mathrm{~mm}$

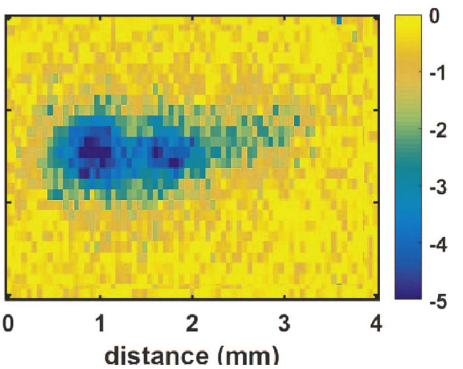

(h) $11 \mathrm{~mm} / 11 \mathrm{~mm}$

Figure 14. The average electric field through the thickness of the crystal $\left(\mathrm{kV} \mathrm{cm}^{-1}\right)$ measured for different locations of the grounded ring at $7 \mathrm{~mm}$ from the target. As such there is a varying source size/travelling distance.

when the jet is in closer proximity to the target. As can be seen from figures 8(a) and (c), the spot is clearly distinguishable from the subsequently forming tail. The spot is smaller than $0.8 \mathrm{~mm}$, while if the tail is present the entire discharge length is larger than $1.75 \mathrm{~mm}$, see figure 17 .

In order to find the origin of the newly formed tail, values of flow, voltage amplitude, travelling distance, source size and distance to the crystal were scanned in over 300 measurements. It has been shown in figures 9,11 and 16 that at least $200 \mathrm{pC}$ has to be deposited at the spot around the impact point for the extended discharge to be present. When enough charge is deposited at the surface, electric fields are high enough for the initialization of a new wave front creating the tail.

For the appearance of the tail an average field through the crystal of $5 \pm 1 \mathrm{kV} \mathrm{cm}^{-1}$ is needed. This relates to $9 \pm 2 \mathrm{kV}$ $\mathrm{cm}^{-1}$ on the crystal surface, see figure 17 . Electric field values relate to values found both experimentally [31] and numerically [32], though the field is induced in the target due to charges deposited instead of measured directly in the plasma plume itself. Also, Sretenović et al showed higher electric field values further in the plume away from the jet [33]. This relates to observations from figure 7 where the highest values are measured with the largest distance between the plasma jet and the target.

Since the tail is a newly formed discharge, the amount of charge in the spot is believed to be directly related to the amount of charge being transferred in a single guided ionization wave. Depending on the plasma jet operating parameters the total surface charge of the initial spot and the extending tail can reach $950 \mathrm{pC}$. The amount of charge that is transferred by the ionization wave from the jet to the dielectric target is maximally $350 \pm 40 \mathrm{pC}$.
Using Lissajous cycles, Dang Van Sung Mussard et al also obtained the charge in a single ionization wave, between 0.3 and $12.7 \mathrm{nC}$ depending on the operating parameters [34]. However jet configuration (pin-to-ring), operating parameters $(10 \mathrm{kV}$ applied voltage) and method of obtaining the charge (metallic probes present) are different. By using metallic probes, the discharges are disturbed in an additional way, which does not happen when using a dielectric target. With a dielectric target the plasma that is under investigation should be closely related to the plasma applied in practice to e.g. skin tissue, water or other dielectric surfaces. As such this paper brings for the first time values of charge via a non-intrusive method.

From the obtained charge value an estimate is made for the average number charge density. Using the diameter of the spot (approximately $0.8 \mathrm{~mm}$ ) to calculate and estimate the volume of a single ionization wave, the number charge density is estimated to be $8 \cdot 10^{18} \mathrm{~m}^{-3}$. For DC pulsed helium-inair generated guided ionization waves the computated number charge densities presented in the literature are similar, (1-10) $\cdot 10^{19} \mathrm{~m}^{-3}$ [35], $10^{18} \mathrm{~m}^{-3}$ [36], $10^{11}-10^{13} \mathrm{~cm}^{-3}$ [37] and $10^{19} \mathrm{~m}^{-3}[38]$.

\subsection{The effect of helium flow and applied voltage}

Results in figures 8 and 9 show the influence of applied gas flow for the resulting surface charge at the target. With higher gas flow the surface discharges are first prolonged and then widened. As has been shown by imaging [11] and here with the electric field profiles, at high enough flows the initiated surface discharge (the tail) forms in a structure with two propagating arms, widening the structure on the surface, see figure 12. Imaging shows higher light intensity at the edges of 


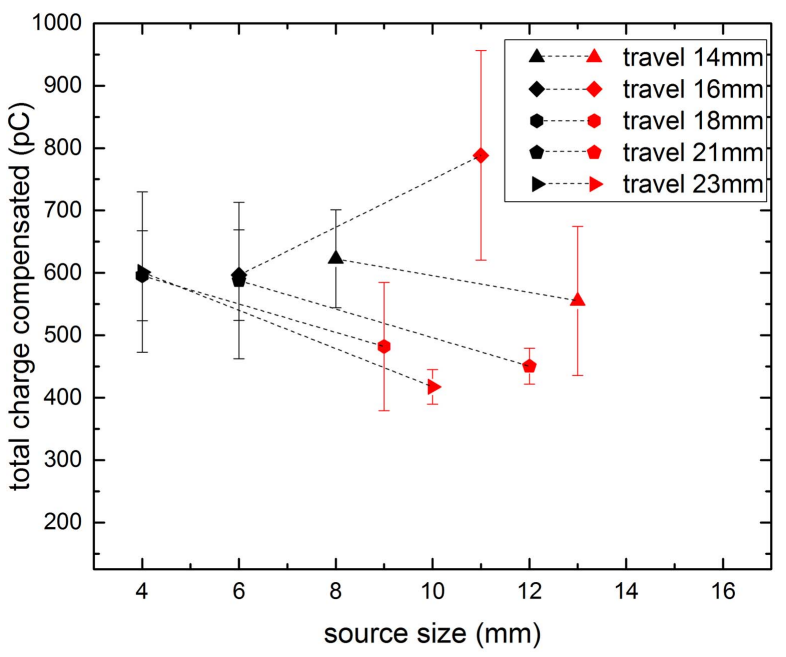

(a) $5 \mathrm{~mm}$

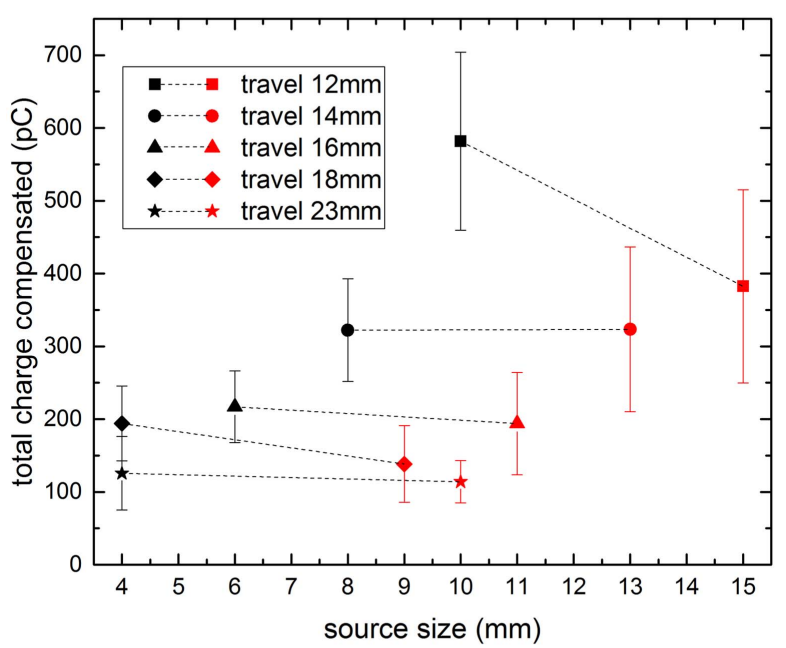

(b) $7 \mathrm{~mm}$

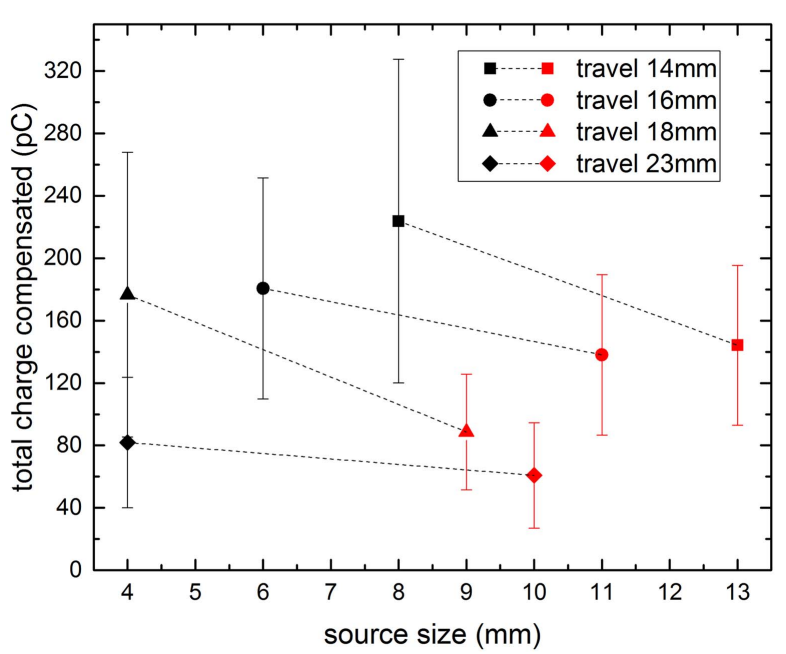

(c) $10 \mathrm{~mm}$

Figure 15. The calculated and compensated amount of total charge deposited at the target for varying source size while having constant travelling distances. For larger source sizes, it is more challeging to sustain the discharge.

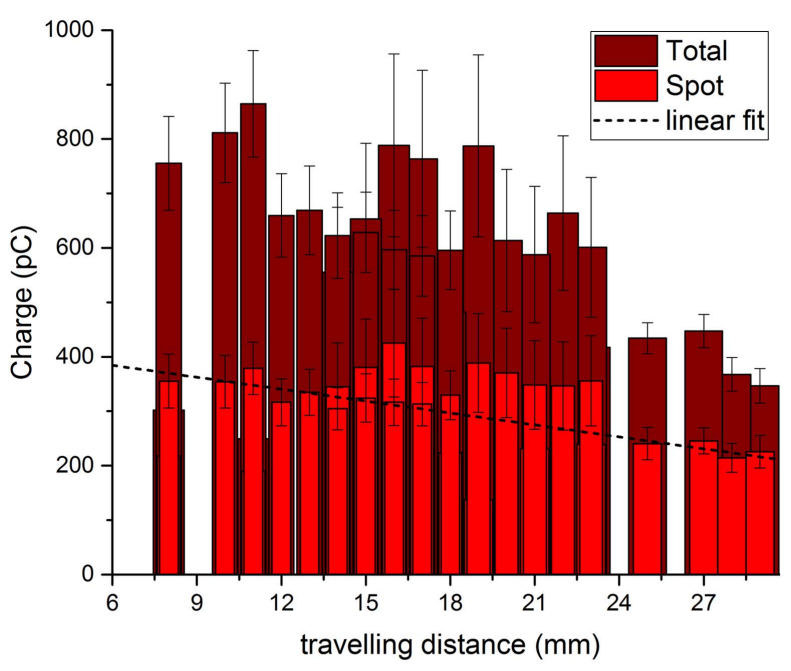

(a) $5 \mathrm{~mm}$

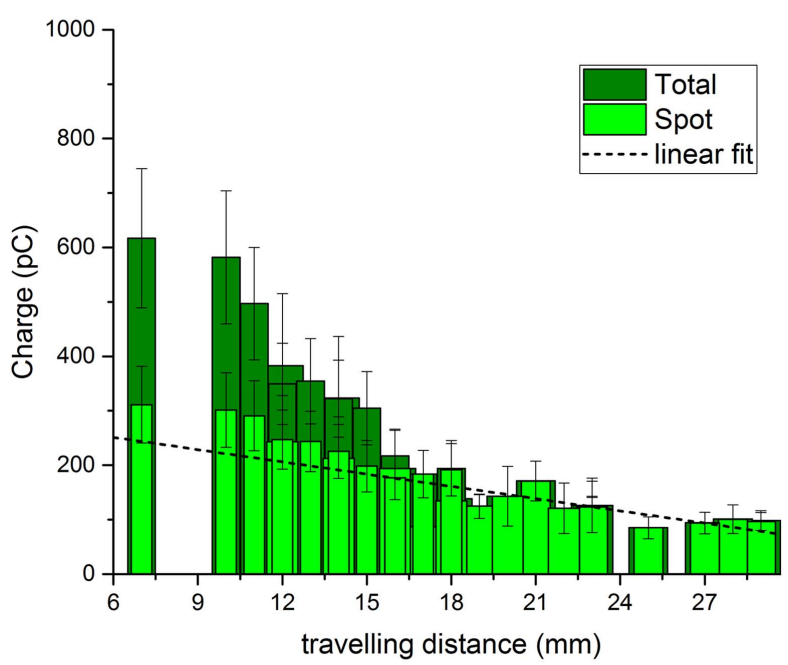

(b) $7 \mathrm{~mm}$

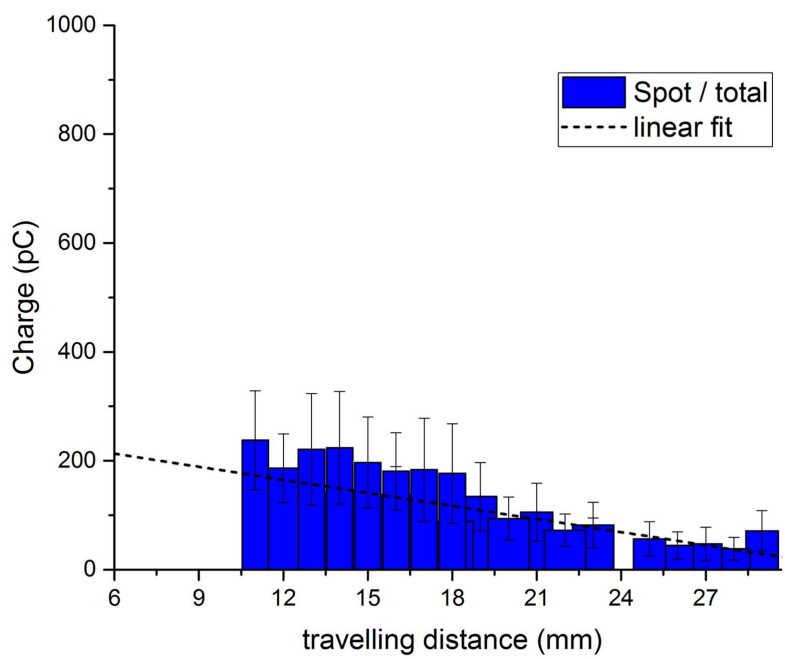

(c) $10 \mathrm{~mm}$

Figure 16. The amount of total charge as a function of travelling distance. Since multiple capillaries are used with varying length some measurements overlap. Linear fits are added for the charge deposited in the spot. 
$0.8 \quad 1.75$

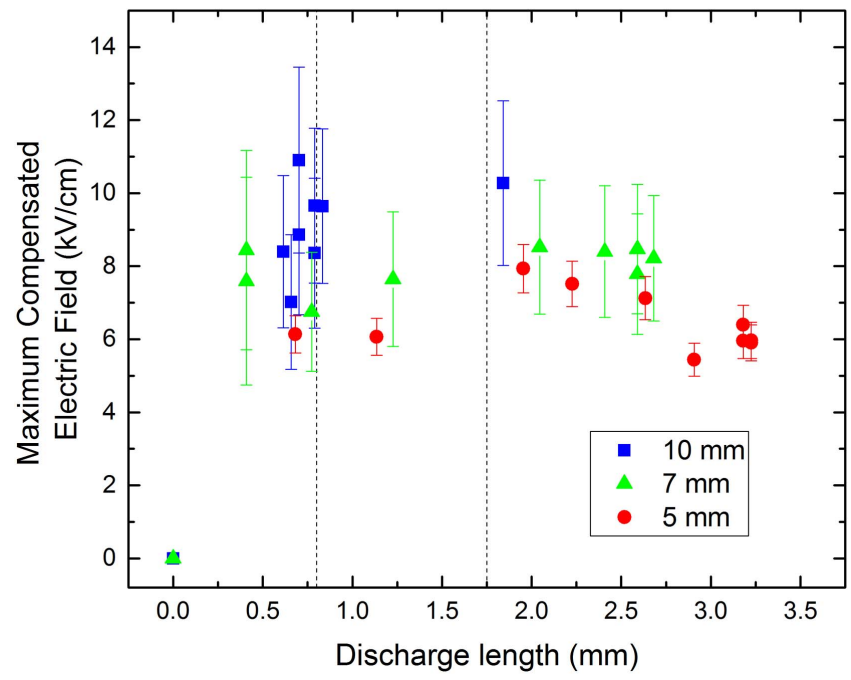

Figure 17. The maximum electric field values $\left(\mathrm{kV} \mathrm{cm}^{-1}\right)$ as a function of discharge length for varying flow. Values at the surface are estimated to be $9 \pm 2 \mathrm{kV} \mathrm{cm}^{-1}$ in the spot, before the discharge is enlarged from a single spot (smaller than $0.8 \mathrm{~mm}$ ) to the extending tail (larger than $1.75 \mathrm{~mm}$ ). The two points in between these regimes, could be due to the averaging of 50 measurements.

this structure [11] and that is also where the electric field is highest.

The increase in the length of the surface discharge relates to the increase of plume length with higher gas flow in the laminar regime, most likely due to a change in gas mixing [39-43]. With higher helium gas flows there will be less air entrained into the volume where the ionization wave propagates both in the space between the capillary as well as on the target.

The widening of the surface discharge and splitting up into two extending arms could have the same origin as the appearance of the ring structure when the ionization waves leave the capillary $[41,44]$. Due to helium in air mixing a region is formed where the energetic electrons from the ionization wave are able to ionize nitrogen, which has a lower ionization level than helium, while the losses due to attachment to oxygen are minimal. At higher flows the edges of the mixing region are far enough apart from each other for the two extending arms to be visible, see figure 12. However more research on gas flow mixing is necessary, especially when a target is present.

The dependence on applied voltage has been examined and described in the literature with regard to plume length $[13,39,41,42,45,46]$. A gradual increase of plume length is observed with increasing voltage, until a certain point where the growth of plume length stagnates. Most likely this is also related to helium/air mixing, determining the maximum plume length. These findings relate to the shape of discharge observed for which the electric field is captured in figure 10 . An initial increase of the discharge is observed, until it stagnates.

This is also visible in figure 11. At $5 \mathrm{~mm}$ a maximum amount of charge is $650 \mathrm{pC}$, which is the same as can be seen in figure 9 for $700 \mathrm{sccm}$. Also at $7 \mathrm{~mm}$ and at $5 \mathrm{~mm}$ the amount of charge stagnates at respectively 200 and 120 pC, because the flow is kept constant at $700 \mathrm{sccm}$.

There is no additional effect due to voltage. It determines how much the discharge is able to utilize the conditions set by the gas flow. Higher gas flow induces a different gas mixing with less oxygen and more helium along the axis of propagation for the ionization waves. As such the ionization waves are exposed to fewer losses due to attachment and are able to move further and deposit more charge on the target if the voltage is increased. However if the voltage is increased when the gas flow is low this will not have that effect, since the losses due to higher oxygen levels are dominant. As such gas mixing is most important, and the effect of voltage is secondary, since the extension is always limited by how far the ionization waves are 'allowed' to travel by the gas mixing. This is clearly shown in figures 12 and 13. If a strong overvoltage would be applied the effect of voltage might not be secondary.

\subsection{The influence of travelling distance: amount of charge lost on the inner side of the capillary}

The influence of the travelling distance can be explained by charge losses on the inner wall of the capillary. Larger travelling distance means more interaction and as such a higher loss for the propagating ionization wave. As a result less charge is deposited on the crystal, smaller discharges are observed and lower electric field values are obtained. The dependence on position of the grounded ring around the capillary has not been reported in literature to the best of our knowledge. Jiang et al [47] show that for different widths of the electrode the appearance of the plasma plume changes. Increasing ground width and consequently decreasing travelling distance causes the plasma plume to reach greater length, similar to observations presented in figure 14 .

Using figure 16 an estimation can be made for the loss per millimetre of travelling distance on the inside of the capillary. With a linear approximation both the initial charge and loss per millimetre to the capillary wall are obtained. The initial amount of charge does differ at different distances, which can be because of a different gas mixing between the jet and the target since the distance is altered. The extrapolated value of the initial charge gives an estimate of the amount of charge leaving the capillary.

Approximately $7.5 \pm 1 \mathrm{pC}$ of charge is lost per millimetre of capillary added to the travelling distance. It corresponds to $0.1 \mathrm{nC} \mathrm{cm}^{-2}$ using the inner dimensions of the capillary. Jánský et al [48] reported $4 \mathrm{nC} \mathrm{cm}^{-2}$ from simulations under the grounded electrode. Other numerical work by Jánský et al [49] gives values inside the capillary ranging from 30 to $50 \mathrm{nC} \mathrm{cm}^{-2}$, however these higher values are for an air discharge which requires a higher voltage to ignite. The charge loss per millimetre of travelling distance depends most likely on the tube properties, e.g. diameter and permittivity, as suggested in simulations [49]. 


\section{Conclusions}

Operating parameters for an atmospheric pressure plasma jet are examined by measuring the electric field using a Pockels technique. The electric field profile measured in the electrooptic BSO crystal is used to calculate the amount of charge transferred to the surface by the guided ionization wave. The use of a look-up table is proposed to compensate for the values obtained from the inappropriate use of the uniform field approximation, since the surface discharges are of the same order of size as the thickness of the crystal.

Electric field profiles captured show the existence of a spot at the impact point of the ionization wave and an extending tail discharge behind it. The field measured in the spot relates to the charge transferred by the ionization wave. A minimal amount of charge of $200 \mathrm{pC}$ is needed in the spot at the impact point for an extended discharge to be present. With this extending tail the amount of charge can be increased up to $950 \mathrm{pC}$ for high enough gas flow. The charge transferred by the guided ionization wave is measured to be maximally $350 \pm 40 \mathrm{pC}$. The number charge density is estimated to be $8 \cdot 10^{18} \mathrm{~m}^{-3}$. Electric field profiles fit very well with the profile of emitted light reported in [11].

The ionization wave greatly depends on the gas flow. At every distance from the target the flow can be increased to an extent at which enough charge is deposited in the impact point for the tail to emerge. The hypothesis is that the gas mixing sets the boundaries for where the guided ionization waves are 'allowed' to be generated and the applied voltage determines how much of this potential region is utilized.

As such, the applied voltage is less influential for ionization waves. Initially an increase of voltage causes larger surface discharge to form and more charge will be deposited, resulting in higher fields that are measured. For higher voltages this effect stagnates, which could be due to helium/air mixing determining the maximum discharge length.

The influence of the jet design is investigated as well. The distance between the powered electrode and the ground attached around the capillary does not change the surface discharge induced by the guided ionization waves impinging on the target; unless the source size is more than $15 \mathrm{~mm}$, which makes it challenging to generate stable ionization waves. The travelling distance, i.e. distance from ground to the end of capillary, does influence the surface discharge. Increasing this distance enlarges wall interactions and smaller discharges are observed at the target. Less charge is deposited and the extending discharge behind the spot is only generated when the jet is close to the crystal. A value for charge loss along the capillary tube is reported, i.e. $7.5 \mathrm{pC} \mathrm{mm}^{-1}$, for the first time in a non-intrusive manner.

\section{References}

[1] Stoffels E, Flikweert A J, Stoffels W W and Kroesen G M W 2002 Plasma Sources Sci. Technol. 11 383-8

[2] Stoffels E, Kieft I E, Sladek R E J, Laan E P V D and Steinbuch M 2006 Plasma Sources Sci. Technol. 15 169-80
[3] Iza F, Kim G J, Lee S M, Lee J K, Walsh J L, Zhang Y T and Kong M G 2008 Plasma Process. Polym. 5 322-44

[4] Fridman G, Friedman G, Gutsol A, Shekhter A B, Vasilets V N and Fridman A 2008 Plasma Process. Polym. 5 503-33

[5] Laroussi M 2009 IEEE Trans. Plasma Sci. 37 714-25

[6] Bárdos L and Baránková H 2010 Thin Solid Films 518 6705-13

[7] Kong M G, Kroesen G, Morfill G, Nosenko T, Shimizu T, van Dijk J and Zimmermann J L 2009 New J. Phys. 11 115012

[8] Lu X, Naidis G V, Laroussi M and Ostrikov K 2014 Phys. Rep. 540 123-66

[9] Lu X, Laroussi M and Puech V 2012 Plasma Sources Sci. Technol. 21034005

[10] Laroussi M and Leipold F 2004 Int. J. Mass Spectrometry 233 81-6

[11] Guaitella O and Sobota A 2015 J. Phys. D: Appl. Phys. 48 255202

[12] Slikboer E, Guaitella O and Sobota A 2016 Plasma Sources Sci. Technol. 25 03LT04

[13] Jarrige J, Laroussi M and Karakas E 2010 Plasma Sources Sci. Technol. 19065005

[14] Wu S, Huang Q, Wang Z and Lu X 2011 IEEE Trans. Plasma Sci. 39 2286-7

[15] Wild R, Gerling T, Bussiahn R, Weltmann K D and Stollenwerk L 2014 J. Phys. D: Appl. Phys. 47042001

[16] Sobota A, Guaitella O and Garcia-Caurel E 2013 J. Phys. D: Appl. Phys. 46327001

[17] Kawasaki T, Terashima T, Zhu Y C, Takada T and Maeno T 1994 J. Phys. D: Appl. Phys. 27 1646-52

[18] Robert E, Darny T, Dozias S, Iseni S and Pouvesle J M 2015 Phys. Plasmas 22122007

[19] Gégot F, Callegari T, Aillerie M and Boeuf J P 2008 J. Phys. D: Appl. Phys. 41135204

[20] Tayag T J, Batchman T E and Sluss J J 1992 Appl. Opt. 31 $625-9$

[21] http://mt-berlin.com/frames_cryst/descriptions/photoref.htm

[22] Bogaczyk M, Wild R, Stollenwerk L and Wagner H E 2012 J. Phys. D: Appl. Phys. 45465202

[23] Kawasaki T, Arai Y and Takada T 1991 Japan. J. Appl. Phys. 30 1262-5

[24] Zhu Y, Takada T and Tu D 1995 J. Phys. D: Appl. Phys 28 1468-77

[25] Stollenwerk L, Laven J G and Purwins H G 2007 Phys. Rev. Lett. 98 1-4

[26] Norberg S A, Johnsen E and Kushner M J 2016 J. Phys. D: Appl. Phys. 49185201

[27] Mu H and Zhang G 2011 Plasma Sci. Technol. 13 645-50

[28] Norberg S A, Johnsen E and Kushner M J 2015 J. Appl. Phys. 118013301

[29] Pechereau F and Bourdon A 2014 J. Phys. D: Appl. Phys. 47 445206

[30] Sobota A, Guaitella O and Rousseau A 2014 Plasma Sources Sci. Technol. 23025016

[31] Bourdon A, Darny T, Pechereau F, Pouvesle J M, Viegas P, Iséni S and Robert E 2016 Plasma Sources Sci. Technol. 25 035002

[32] Sretenovic G B, Krstic I B, Kovacevic V V, Obradovic B M and Kuraica M M 2011 Appl. Phys. Lett. 99161502

[33] Sretenović G B, Krstić I B, Kovačević V V, Obradović B M and Kuraica M M 2014 J. Phys. D: Appl. Phys. 47102001

[34] Dang Van Sung Mussard M, Foucher E and Rousseau A 2015 J. Phys. D: Appl. Phys. 48424003

[35] Sakiyama Y, Graves D B, Jarrige J and Laroussi M 2010 Appl. Phys. Lett. 96 2-4

[36] Liu X Y, Pei X K, Lu X P and Liu D W 2014 Plasma Sources Sci. Technol. 23035007 
[37] Naidis G V 2010 J. Phys. D: Appl. Phys. 43402001

[38] Breden D, Miki K and Raja L L 2011 Appl. Phys. Lett. 99 2009-12

[39] Karakas E, Koklu M and Laroussi M 2010 J. Phys. D: Appl. Phys. 43155202

[40] Xiong R, Xiong Q, Nikiforov A Y, Vanraes P and Leys C 2012 J. Appl. Phys. 112 1-9

[41] Mericam-Bourdet N, Laroussi M, Begum A and Karakas E 2009 J. Phys. D: Appl. Phys. 42055207

[42] Zhu W C, Li Q, Zhu X M and Pu Y K 2009 J. Phys. D: Appl. Phys. 42202002
[43] Park H S, Kim S J, Joh H M, Chung T H, Bae S H and Leem S H 2010 Phys. Plasmas 17244108

[44] Teschke M, Kedzierski J, Finantu-Dinu E, Korzec D and Engemann J 2005 IEEE Trans. Plasma Sci. 33 310-1

[45] Xiong Q, Lu X, Ostrikov K, Xiong Z, Xian Y, Zhou F, Zou C, Hu J, Gong W and Jiang Z 2009 Phys. Plasmas 16043505

[46] Naidis G V 2012 J. Appl. Phys. 112 0-5

[47] Jiang N, Ji A and Cao Z 2010 J. Appl. Phys. 108033302

[48] Jánský J, Algwari Q T, O'Connell D and Bourdon A 2012 IEEE Trans. Plasma Sci. 40 2912-9

[49] Jánský J and Bourdon A 2011 Eur. Phys. J. Appl. Phys. 11-14 